\title{
Isothiourea-Catalyzed Enantioselective Addition of 4-Nitrophenyl Esters to Iminium Ions
}

\author{
Jude N. Arokianathar, ${ }^{a}$ Aileen B. Frost, ${ }^{a}$ Alexandra M. Z. Slawin, ${ }^{a}$ Darren Stead ${ }^{b}$ and Andrew D. \\ Smith*a
}

${ }^{a}$ EaStCHEM, School of Chemistry, University of St Andrews, North Haugh, St Andrews, KY16 9ST.

${ }^{b}$ AstraZeneca, IMED Oncology, Darwin Building, Unit 310, Cambridge Science Park, Milton Rd, Cambridge, CB4 0WG.

\begin{abstract}
Isothioureas catalyze the enantioselective addition of 4-nitrophenyl esters to tetrahydroisoquinoline-derived iminium

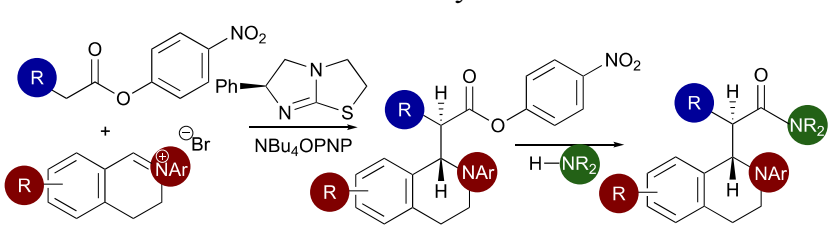
ions. 4-Nitrophenoxide, generated in situ from initial $N$-acylation of the isothiourea by the 4-nitrophenyl ester, is used to facilitate catalyst turnover in this reaction process. Optimization showed that 4nitrophenyl esters give the best reactivity in this protocol over a range of alternative aryl esters, with the observed enantioselectivity markedly dependent upon the nature of the iminium counterion. Highest - Aryloxide turnover · Counterion dependent selectivity - 24 examples $\sim 75: 25$ dr up to 99.5:0.5 er yields and enantioselectivity were obtained using iminium bromide ions generated in situ via photoredox catalysis using $\mathrm{BrCCl}_{3}$ and $\mathrm{Ru}(\mathrm{bpy})_{3} \mathrm{Cl}_{2}(0.5 \mathrm{~mol} \%)$ and commercially available tetramisole $(5$ mol\%) as the Lewis base catalyst. The scope and limitations of this procedure was developed, giving the desired $\beta$-amino amide products in up to $96 \%$ yield, $79: 21 \mathrm{dr}$ and er $_{\text {major }\left(2 R, 1^{\prime} S\right)} 99.5: 0.5$.
\end{abstract}

\section{KEYWORDS: isothiourea; iminium ion; counterion dependent enantioselectivity}

\section{INTRODUCTION}

Ammonium enolate intermediates ${ }^{1}$ generated by the action of tertiary amines ${ }^{2}$ in Lewis base catalysis ${ }^{3}$ have found widespread application in chiral heterocycle synthesis via formal cycloaddition reactions, with many diverse scaffolds accessible in high yields and excellent enantiocontrol. While traditional strategies for ammonium enolate generation utilize the direct reaction of a Lewis base with ketenes, ${ }^{4}$ more recently the use of bench-stable carboxylic acids, ${ }^{5}$ anhydrides ${ }^{6}$ or acyl imidazoles $^{7}$ as ammonium enolate precursors have also been employed. The nucleophilic ammonium enolate generated in situ reacts with an electrophilic reagent containing a latent nucleophile to generate a species capable of catalyst turnover in an intramolecular fashion (Figure 1, eqn 1). This approach represents a key limitation in this branch of catalysis, with ammonium enolate chemistry typically applied in formal $[2+2],{ }^{8}[3+2]^{9}$ or $[4+2]^{10}$ cycloaddition methodologies. The established exception to this reactivity issue is the pioneering work from Lectka and co-workers in the area of enantioselective halogenations (Figure 1, eqn 2). ${ }^{11}$ In a series of elegant manuscripts polyhalogenated quinones were used to affect enantioselective halogenation of an ammonium enolate. ${ }^{12}$ Enolate addition to an electrophilic polyhalogenated quinone results in formation of an ammonium aryloxide ion pair, with the aryloxide generated in situ used for catalyst turnover. ${ }^{13}$ Further seminal work in exploiting aryloxide "rebound" catalysis was reported by Scheidt, ${ }^{14}$ who applied this concept to an NHC-catalyzed formal Mannich process, utilizing $\alpha$ aryloxyaldehydes as azolium enolate precursors (Figure 1, eqn 3).

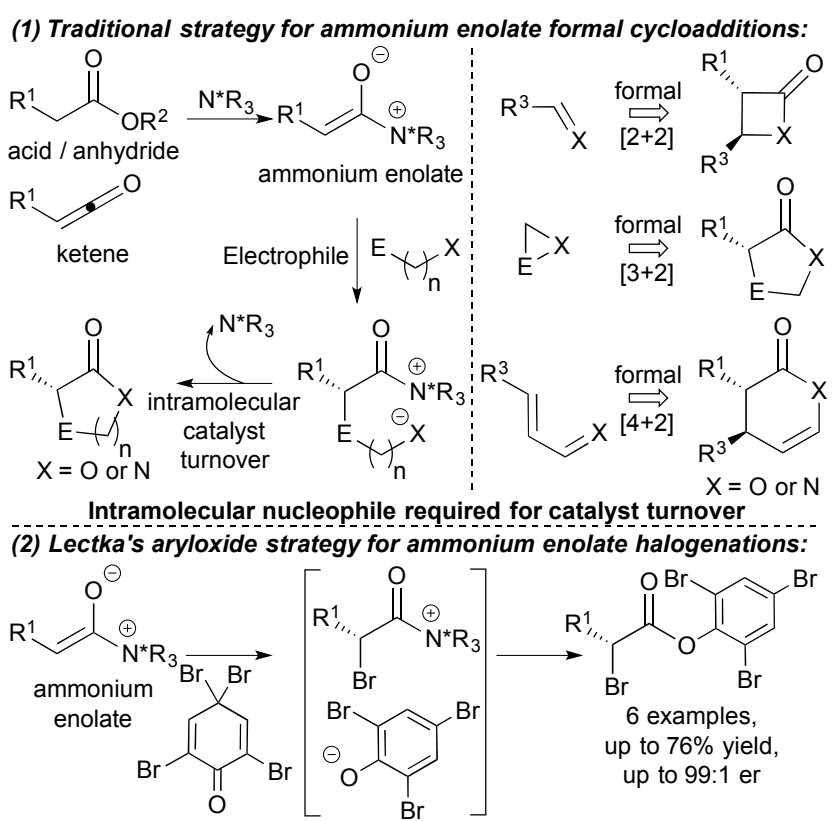

Aryloxide generated in situ used for catalyst turnover (3) Scheidt's NHC-catalyzed aryloxide "rebound" catalysis:

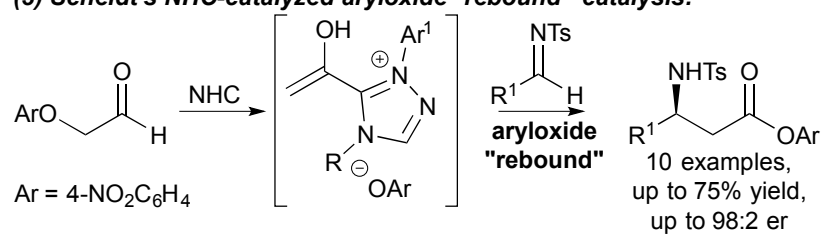

Figure 1. Strategies for catalyst turnover in ammonium enolate catalysis 
More recently, activated aryl esters have emerged as alternative enolate precursors, offering a potentially general solution to this challenge. ${ }^{15}$ An attractive feature of aryl ester substrates is the potential ability of the aryloxide, liberated upon initial catalyst acylation, to assist catalyst turnover. Expanding on Chi's use of aryl esters in NHC-catalyzed formal cycloadditions (in which the aryloxide generated upon acylation of the NHC serves solely as a leaving group and is not required to promote turnover), ${ }^{16}$ in 2014 we developed an isothioureacatalyzed [2,3]-rearrangement of allylic ammonium ylides. In this process catalyst turnover relied on in situ formed aryloxide, ${ }^{17}$ with a HOBt co-catalyst necessary for optimum reactivity (Figure 2, eqn 1). ${ }^{18}$ Aryloxides have also been utilized stoichiometrically as catalyst turnover agents by $\mathrm{Fu}$ and coworkers in the chiral DMAP-catalyzed $\alpha$-fluorination of ketenes. ${ }^{19}$ Recent reports by first Snaddon (Figure 2, eqn 2 ) ${ }^{20}$ and subsequently Hartwig (Figure 2, eqn 3$)^{21}$ have elegantly applied this idea in co-operative isothiourea/metal-catalyzed enolate allylation reactions using pentafluorophenyl ester precursors. In both cases, an isothiourea-derived ammonium enolate reacts with a metal $\pi$-allyl complex to affect the allylation reaction. Snaddon employed palladium catalysis to give a range of $\alpha$-allyl esters in up to 95\% yield and 99:1 er, whereas Hartwig used a chiral iridium catalyst that preferentially gives the branched regioisomeric products in up to $99 \%$ yield, $>20: 1$ $\mathrm{dr}$ and $>99: 1 \mathrm{er}$. Through judicious pairing of the enantiomers of each chiral catalyst all four possible diastereoisomers of the product were prepared with excellent enantioselectivity.

(1) Smith: [2,3]-rearrangement of allylic ammonium ylides
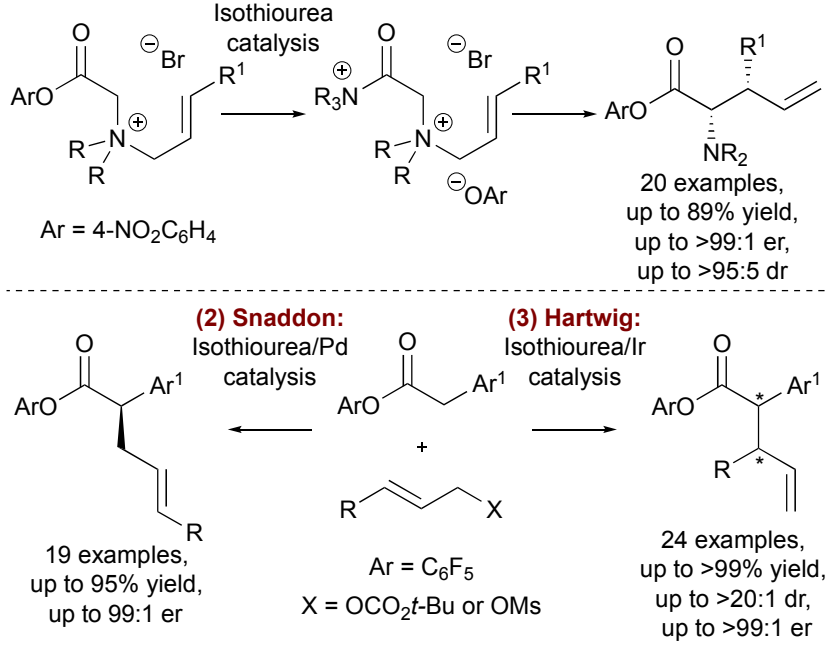

Figure 2. Recent work exploiting in situ generated aryloxide to provide catalyst turnover

Building upon these precedents, it was envisaged that tetrahydroisoquinoline derived iminium ions could act as stoichiometric reactive electrophiles using ammonium enolates generated from aryl esters. Importantly, catalyst turnover in this intermolecular process could only be achieved using a exogenous nucleophile to promote catalyst release (in this case an aryloxide generated in situ from an aryl ester). In this process, $\mathrm{N}$-acylation of the isothiourea catalyst $\mathbf{1}$ with an activated aryl ester 2 would generate the corresponding acyl ammonium aryloxide ion pair $\mathbf{3}$, with subsequent deprotonation leading to ammonium enolate 4 (Figure 3 ). Reaction of ammonium enolate 4 with iminium electrophile 5 would give intermediate 6 . Catalyst release from intermediate $\mathbf{6}$ cannot be achieved by an intramolecular nucleophile as required for a formal cycloaddition strategy, but instead uses an "external" nucleophile (aryloxide) to provide turnover. The origin of enantiocontrol in isothiourea-catalyzed ammonium enolate transformations is proposed to rely upon an $\mathrm{n}_{\mathrm{o}}$ to $\sigma^{*}{ }_{\mathrm{C}-\mathrm{S}}$ interaction ${ }^{22}$ between the enolate oxygen and catalyst sulfur atom. This formally provides a conformational lock, with subsequent addition preferentially anti- to the phenyl stereodirecting group promoted by the 1,5-syn-coplanar $\mathrm{S} \bullet \cdot \mathrm{O}$ arrangement. Catalyst turnover would be achieved via nucleophilic attack of the aryloxide upon acyl ammonium $\mathbf{6}$, giving the $\beta$-amino ester product 7 . Notably, in the absence of the aryloxide, catalyst turnover could not be achieved using ammonium enolates generated directly at the carboxylic acid oxidation level. This work describes the successful realization of this goal. Notably, the enantioselectivity of this process showed a marked dependence on the nature of the iminium counterion, with the optimized protocol using photoredox catalysis to generate the key reactive iminium bromide salt in situ.

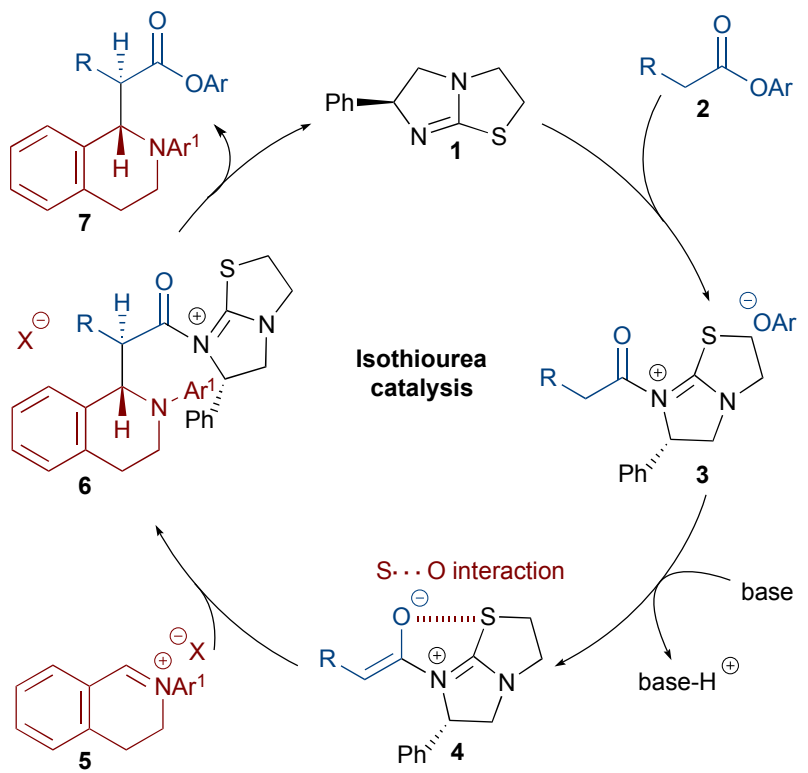

Figure 3. This work: isothiourea-catalyzed enantioselective addition to iminium ions

\section{RESULTS AND DISCUSSION}

Initial proof of concept studies. Proof of principle investigations began on a simplified model system to demonstrate the feasibility of in situ generated aryloxide to provide turnover in this process. Iminium ion $\mathbf{1 1}$ was isolated via stoichiometric oxidation of $N$-phenyl tetrahydroisoquinoline with $\mathrm{DDQ}^{23}$ and used in optimization studies for the isothiourea-catalyzed process. Iminium 11 and activated 4-nitrophenyl (PNP) ester 8 were treated with benzotetramisole (BTM) $13(20 \mathrm{~mol} \%)$ and $i$ - $\mathrm{Pr}_{2} \mathrm{NEt}$ ( 1.5 equiv) in THF at $-10{ }^{\circ} \mathrm{C}$ for $24 \mathrm{~h}$. Preliminary work indicated that lower isolated yields of the corresponding PNP ester product were obtained than expected by reaction conversion, ${ }^{24}$ consistent with this product being unstable to purification. Consequently, benzylamine $\left(\mathrm{BnNH}_{2}\right)$ was added to form a stable isolable amide product $\mathbf{1 2}$ in $39 \%$ yield and 73:27 dr (Table 1, entry 1: er ${\text { major }\left(2 R, 1^{\prime} S\right)} 72: 28$; $\operatorname{er}_{\text {minor }}\left(2 R, 1^{\prime} R\right)$ $63: 37) .{ }^{25}$ Other isothiourea catalysts were trialed, with HyperBTM 14 giving similar yield and er, but reduced dr (entry 2: 66:34 dr). Tetramisole $\cdot \mathrm{HCl} \mathbf{1} \cdot \mathrm{HCl}$ gave amide $\mathbf{1 2}$ in an improved $64 \%$ yield, whilst maintaining the observed levels of 
diastereo- and enantiocontrol (entry 3: 75:25 dr, er major $\left(2 R, 1^{\prime} S\right)$ 72:28; $\operatorname{er}_{\text {minor }}\left(2 R, 1^{\prime} R\right)$ 59:41). Alternative aryl esters were screened to assess their reactivity and impact on stereoselectivity. The reaction of iminium 11 with 2,4,6-trichlorophenyl ester 9 in the presence of $\mathbf{1} \cdot \mathrm{HCl}$ produced no observable product (entry 4), while 3,5-bis(trifluoromethyl)phenyl ester $\mathbf{1 0}$ gave the amide product 12 in 71:29 dr $\left(\mathrm{er}_{\text {major }\left(2 R, 1^{\prime} S\right)} 94: 6\right.$; $\mathrm{er}_{\text {minor }}$ $\left.\left(2 R, 1^{\prime} R\right) 85: 15\right)$ but in a poor $22 \%$ yield (entry 5 ). The use of alternative 2,3,5,6-tetrafluoro- and pentafluorophenyl esters gave poor $(<5 \%)$ product yields. ${ }^{26}$ No product was observed in the absence of $1 \cdot \mathrm{HCl}$ when the PNP ester 8 was used, indicating no competitive base-mediated background reaction being operative under these conditions (entry 6).

Table 1. Initial proof of concept studies ${ }^{a}$
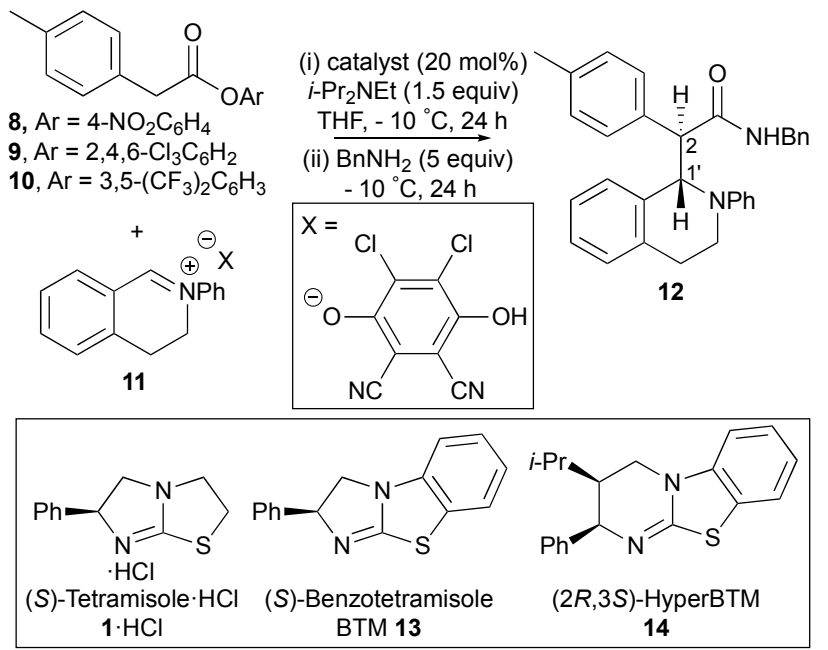

\begin{tabular}{|c|c|c|c|c|c|c|}
\hline Entry & $\mathrm{Ar}$ & Catalyst & $\mathrm{dr}^{b}$ & $\begin{array}{l}\text { Yield } \\
(\%)^{c}\end{array}$ & $\begin{array}{l}\mathrm{er}_{\text {major }} \\
\left(2 R, 1^{\prime} S\right)^{d}\end{array}$ & $\begin{array}{l}\mathrm{er}_{\text {minor }} \\
\left(2 R, 1^{\prime} R\right){ }^{d}\end{array}$ \\
\hline 1 & 8 & 13 & $73: 27$ & 39 & $72: 28$ & $63: 37$ \\
\hline 2 & 8 & 14 & $66: 34$ & 40 & $73: 27$ & $52: 48$ \\
\hline 3 & 8 & $\mathbf{1} \cdot \mathrm{HCl}$ & $75: 25$ & 64 & $72: 28$ & $59: 41$ \\
\hline 4 & 9 & $\mathbf{1} \cdot \mathrm{HCl}$ & - & - & - & - \\
\hline 5 & 10 & $\mathbf{1} \cdot \mathrm{HCl}$ & $71: 29$ & 22 & $94: 6$ & $85: 15$ \\
\hline 6 & 8 & - & - & - & - & - \\
\hline
\end{tabular}

${ }^{a}$ Reaction conditions: (i) 11 ( 1 equiv, $0.25 \mathrm{mmol}$ ), 8-10 (1.5 equiv), catalyst $(20 \mathrm{~mol} \%), i-\operatorname{Pr}_{2} \mathrm{NEt}$ ( 1.5 equiv), THF $(0.18 \mathrm{M}),-10{ }^{\circ} \mathrm{C}, 24 \mathrm{~h}$; (ii) $\mathrm{BnNH}_{2}$ (5 equiv), $-10{ }^{\circ} \mathrm{C}, 24 \mathrm{~h} .{ }^{b} \mathrm{dr}$ of crude product determined by ${ }^{1} \mathrm{H}$ NMR spectroscopic analysis. ${ }^{c}$ Isolated yields given as a mixture of diastereoisomers. Only the major diastereoisomer is shown. ${ }^{d}$ er of major and minor diastereoisomers determined by chiral HPLC analysis.

\section{Reaction Optimization.}

(a) Additive and solvent screen. Previous work in catalytic enantioselective [2,3]-rearrangements from our laboratory has identified the role of additives in improving reaction enantioselectivity. ${ }^{17}$ Addition of tetrabutylammonium bromide 15 (1 equiv) to the $\mathbf{1} \cdot \mathrm{HCl}$-catalyzed reaction of iminium 11 and ester 8 resulted in a significant enhancement in enantioselectivity (Table 2, entry 1: $\operatorname{er}_{\text {major }\left(2 R, 1^{\prime} S\right)} 89: 11$; er $\left._{\text {minor }\left(2 R, 1^{\prime} R\right)} 80: 20\right)$, however the isolated yield dropped to $32 \%$. Addition of tetrabutylammonium 4-nitrophenoxide (TBAPNP) 16 maintained this improved enantioselectivity and increased the yield to $63 \%$ (entry 2). This increase is likely due to a combination of increased polarity of the reaction mixture and the influence of 4nitrophenoxide in facilitating catalyst turnover. A dual combi- nation of 16 ( 1 equiv) and HOBt 17 (1 equiv) was attempted, but led to a decreased yield of 54\% without any improvement in stereoselectivity (entry 3). Performing the reaction with only $\mathbf{1 6}$ as an additive and in the absence of $\mathbf{1} \cdot \mathrm{HCl}$ confirmed that no competitive background reaction was operative under these conditions (entry 4). Additional controls confirmed that the observed diastereomeric ratio is consistent throughout the course of the reaction, and is thus not the result of epimerization by $\mathrm{BnNH}_{2}{ }^{27}$ A solvent screen showed that $\mathrm{MeCN}$ (entry 5) and $\mathrm{CH}_{2} \mathrm{Cl}_{2}$ (entry 6) were the only other solvents to give good conversion to product, albeit with reduced enantioselectivity (Table 2).

Table 2. Additive and solvent $\operatorname{screen}^{a}$
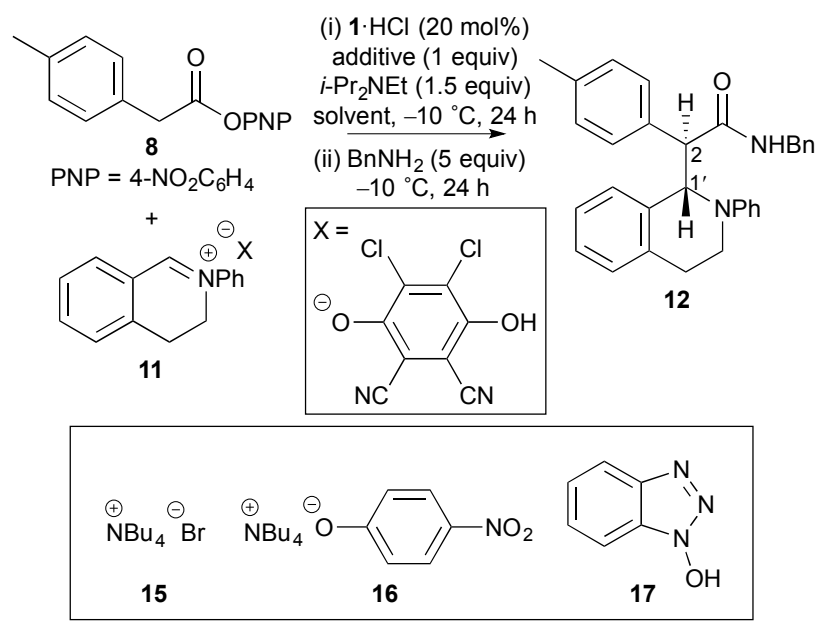

$\begin{array}{ccccccc}\text { Entry } & \begin{array}{c}\text { Additive } \\ \text { (1 equiv) }\end{array} & \text { Solvent } & \mathrm{dr}^{b} & \begin{array}{c}\text { Yield } \\ (\%)^{c}\end{array} & \begin{array}{c}\mathrm{er}_{\text {major }} \\ \left(2 R, 1^{\prime} S\right)^{d}\end{array} & \begin{array}{c}\mathrm{er}_{\text {minor }} \\ \left(2 R, 1^{\prime} R\right)\end{array} \\ 1 & \mathbf{1 5} & \text { THF } & 72: 28 & 32 & 89: 11 & 80: 20 \\ 2 & \mathbf{1 6} & \text { THF } & 73: 27 & 63 & 89: 11 & 73: 27 \\ 3 & \mathbf{1 6 , 1 7} & \text { THF } & 76: 24 & 54 & 89: 11 & 70: 30 \\ 4 & \mathbf{1 6} & \text { THF } & - & - & - & - \\ 5 & \mathbf{1 6} & \mathrm{MeCN}^{d} & 83: 17 & 73 & 75: 25 & 66: 34 \\ 6 & \mathbf{1 6} & \mathrm{CH}_{2} \mathrm{Cl}_{2} & 78: 22 & 59 & 80: 20 & 66: 34\end{array}$

${ }^{a}$ Reaction conditions: (i) $\mathbf{1 1}(1$ equiv, $0.25 \mathrm{mmol}), \mathbf{8}(1.5$ equiv), $\mathbf{1} \cdot \mathrm{HCl}(20$ $\mathrm{mol} \%$ ), additive ( 1 equiv), $i$ - $\operatorname{Pr}_{2} \mathrm{NEt}\left(1.5\right.$ equiv), $\operatorname{THF}(0.18 \mathrm{M}),-10^{\circ} \mathrm{C}, 24$ h; (ii) $\mathrm{BnNH}_{2}$ (5 equiv), $-10{ }^{\circ} \mathrm{C}, 24 \mathrm{~h} .{ }^{b} \mathrm{dr}$ of crude product determined by ${ }^{1} \mathrm{H}$ NMR spectroscopic analysis. ${ }^{c}$ Isolated yields given as a mixture of diastereoisomers. Only the major diastereoisomer is shown. ${ }^{d}$ er of major and minor diastereoisomers determined by chiral HPLC analysis.

(b) Effect of the iminium counterion. The effect of the iminium counterion upon reactivity and enantioselectivity was investigated next. A range of iminium ions was prepared by either oxidation using bromotrichloromethane $\left(\mathrm{BrCCl}_{3}\right)$ in the presence of blue light (Table 3 , entry 1) or counterion exchange (entries 2-5) to examine the effect on the yield and selectivity. While the diastereoselectivity of the process was essentially invariant, changing the counterion showed significant variation in yield and enantioselectivity. The smaller, coordinating halide counterions $\left(\mathrm{Br}^{-}\right.$and $\left.\mathrm{Cl}^{-}\right)$gave the amide product 12 in comparable yield to the model system (entries 1 and 2 ) and with improved enantioselectivity ( $\mathrm{er}_{\text {major }\left(2 R, 1^{\prime} S\right)}$ : 97:3 and 96:4 respectively). The larger, non-coordinating counterions $\left(\mathrm{BF}_{4}^{-}, \mathrm{PF}_{6}{ }^{-}\right.$and $\left.\mathrm{BPh}_{4}{ }^{-}\right)$gave higher yields in comparison with the model system (entries 3-5), but with reduced enantioselectivity ( $\mathrm{er}_{\text {major }\left(2 R, 1^{\prime} S\right)}$ : $90: 10,87: 13$ and $82: 18$ ). As the synthesis of iminium bromide $\mathbf{1 8}$ is facile via either oxidation 
using $\mathrm{BrCCl}_{3}$ in the presence of blue light or photoredoxcatalyzed process, the bromide counterion was chosen for all further studies (Table 3).

Table 3. Iminium counterion $\operatorname{effect}^{a}$

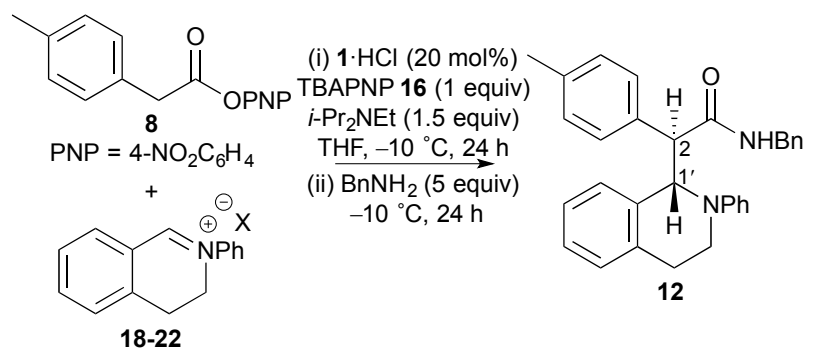

$\begin{array}{cccccc}\text { Entry } & \mathrm{X} & \mathrm{dr}^{b} & \begin{array}{c}\text { Yield } \\ (\%)^{c}\end{array} & \begin{array}{c}\mathrm{er}_{\text {major }}{ }_{\left(2 R, 1^{\prime} S\right)} \\ 1\end{array} & \begin{array}{c}\mathrm{er}_{\text {minor }} \\ \left(2 R, 1^{\prime} R\right)\end{array} \\ 2 & \mathrm{Br}(\mathbf{1 8}) & 74: 26 & 55 & 97: 3 & 96: 4 \\ 3 & \mathrm{Cl}(\mathbf{1 9}) & 72: 28 & 67 & 96: 4 & 95: 5 \\ 4 & \mathrm{BF}_{4}(\mathbf{2 0}) & 80: 20 & 87 & 90: 10 & 75: 25 \\ 5 & \mathrm{PF}_{6}(\mathbf{2 1}) & 77: 23 & 88 & 87: 13 & 70: 30 \\ \mathrm{BPh}_{4}(\mathbf{2 2}) & 76: 24 & 88 & 82: 18 & 67: 33\end{array}$

${ }^{a}$ Reaction conditions: (i) $\mathbf{1 8 - 2 2}(1$ equiv, $0.25 \mathrm{mmol}), \mathbf{8}(1.5$ equiv), $\mathbf{1} \cdot \mathrm{HCl}$ (20 mol\%), TBAPNP 16 ( 1 equiv), $i$-Pr ${ }_{2}$ NEt ( 1.5 equiv), THF $(0.18 \mathrm{M})$, $-10{ }^{\circ} \mathrm{C}, 24 \mathrm{~h}$; (ii) $\mathrm{BnNH}_{2}$ (5 equiv), $-10{ }^{\circ} \mathrm{C}, 24 \mathrm{~h} .{ }^{b} \mathrm{dr}$ of crude product determined by ${ }^{1} \mathrm{H}$ NMR spectroscopic analysis. ${ }^{c}$ Isolated yields given as a mixture of diastereoisomers. Only the major diastereoisomer is shown. ${ }^{d} \mathrm{er}$ of major and minor diastereoisomers determined by chiral HPLC analysis.

(c) Developing a sequential photocatalytic oxidation/isothiourea-catalyzed procedure. The use of photoredox catalysis in recent years has emerged as a powerful tool that has been widely exploited in organic chemistry. ${ }^{28}$ Applications in organocatalysis are being realized, with dual catalytic procedures $^{29}$ involving imidazolidinone, ${ }^{30}$ NHC, ${ }^{31}$ prolinederived, ${ }^{32}$ thiourea ${ }^{33}$ and $\mathrm{DABCO}^{34}$ catalysts already developed. Having shown that highest enantioselectivity was observed using the iminium bromide salt, attention turned to incorporating a photocatalytic oxidation to generate the required iminium ion. Following Zeitler's precedent, ${ }^{35}$ the oxidation of $N$-phenyl tetrahydroisoquinoline 23 using $\mathrm{BrCCl}_{3}$ in THF and irradiation with blue LED light at $\mathrm{rt}$ for $24 \mathrm{~h}$ was followed. Removal of the light source, followed by the organocatalytic step gave amide $\mathbf{1 2}$ in 59\% yield, 75:25 dr and er major $\left(2 R, 1^{\prime} S\right)$ 95:5 (Table 4, entry 1$) .{ }^{36}$ As an alternative, using $\mathrm{Ru}(\mathrm{bpy})_{3} \mathrm{Cl}_{2} 24$ as a photocatalyst $(1 \mathrm{~mol} \%)^{37}$ gave complete oxidation within $2 \mathrm{~h}$, and after organocatalytic functionalization gave the desired product $\mathbf{1 2}$ in a similar yield with no change in diastereo- and enantioselectivity (entry 2). When both photo- and organocatalytic reaction steps were carried out in $\mathrm{MeCN}$ a significant enhancement in yield was observed, with 12 obtained in $77 \%$ yield but with reduced stereoselectivity (entry 3). A screen of THF:MeCN mixtures was carried out to find a system that delivered high yields without compromizing stereoselectivity. To achieve consistently high yields, it was necessary to conduct the oxidation step in MeCN. Increased enantioselectivity in the organocatalytic step was achieved by the addition of THF, with a 3:1 ratio of THF:MeCN being found to be optimal. Under these conditions, amide 12 was isolated in 78\% yield, 77:23 $\mathrm{dr}$ and $\mathrm{er}_{\text {major }}$ $\left(2 R, 1^{\prime} S\right)$ 95:5 (entry 4). Further studies were undertaken to reduce the loading of the two catalyst systems. Reduction of the or- ganocatalyst $1 \cdot \mathrm{HCl}$ loading from $20 \mathrm{~mol} \%$ to $10 \mathrm{~mol} \%$ gave 12 in $65 \%$ (entry 5 ) and 5 mol\% resulted in 12 in $70 \%$ yield with no loss in selectivity (entry 7). Further reduction of the loading of $\mathbf{1} \cdot \mathrm{HCl}$ gave reduced reactivity, with a severely diminished yield observed at $2 \mathrm{~mol} \%$ (entry 9). Although 0.5 mol\% of $\mathrm{Ru}(\mathrm{bpy}){ }_{3} \mathrm{Cl}_{2} 24$ showed a marginally better yield and selectivity than $1 \mathrm{~mol} \%$ when $10 \mathrm{~mol} \%$ of $\mathbf{1} \cdot \mathrm{HCl}$ was used (entry 6), the optimal catalyst loading was $5 \mathrm{~mol} \%$ of $1 \cdot \mathrm{HCl}$ and $0.5 \mathrm{~mol} \%$ of 24 (entry 8 ). Attempts to carry out both photo- and organocatalyzed steps simultaneously, rather than sequentially, were conducted. Reaction catalyzed by $1 \mathrm{~mol} \%$ of $\mathrm{Ru}(\mathrm{bpy})_{3} \mathrm{Cl}_{2} 24$ and $20 \mathrm{~mol} \%$ of $\mathbf{1} \cdot \mathrm{HCl}$ in $\mathrm{MeCN}$ :THF $(2: 1)$ resulted in formation of amide 12 in 57\% yield and 67:33 dr, but only 56:44 er. Under the developed conditions, attempts to utilize either $\mathrm{N}, \mathrm{N}$-dimethylaniline or $\mathrm{N}$-benzyl- $\mathrm{N}$ methylaniline as starting materials rather than $\mathbf{2 3}$ did not lead to any observable product. ${ }^{26}$

Table 4. Optimizing a sequential photoredox/isothioureacatalyzed procedure

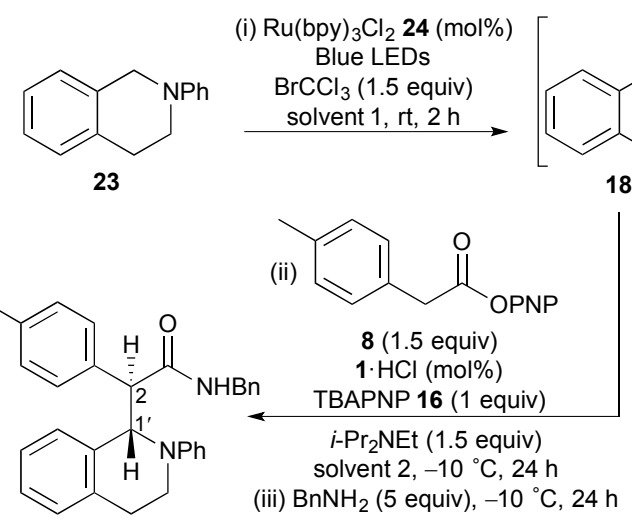

12

$\begin{array}{ccccccc}\text { Entry } & \text { Solvent 1/2 } & \mathbf{2 4}^{a} & \mathbf{1} \cdot \mathrm{HCl}^{a} & \mathrm{dr}^{b} & \begin{array}{c}\text { Yield } \\ (\%)^{c}\end{array} & \begin{array}{c}\mathrm{er}_{\text {major }} \\ \left(2 R, 1^{\prime} S\right)^{d}\end{array} \\ 1^{e} & \mathrm{THF} /- & 0 & 20 & 75: 25 & 59 & 95: 5 \\ 2 & \mathrm{THF} /- & 1 & 20 & 74: 26 & 56 & 95: 5 \\ 3 & \mathrm{MeCN} /- & 1 & 20 & 64: 36 & 77 & 92: 8 \\ 4 & \mathrm{MeCN} / \mathrm{THF}^{f} & 1 & 20 & 77: 23 & 78 & 95: 5 \\ 5 & \mathrm{MeCN} / \mathrm{THF}^{f} & 1 & 10 & 73: 27 & 65 & 94: 6 \\ 6 & \mathrm{MeCN} / \mathrm{THF}^{f} & 0.5 & 10 & 70: 30 & 70 & 95: 5 \\ 7 & \mathrm{MeCN} / \mathrm{THF}^{f} & 1 & 5 & 72: 28 & 70 & 94: 6 \\ 8 & \mathrm{MeCN} / \mathrm{THF}^{f} & 0.5 & 5 & 74: 26 & 78 & 94: 6 \\ 9 & \mathrm{MeCN} / \mathrm{THF}^{f} & 1 & 2 & 70: 30 & 35 & 93: 7\end{array}$

${ }^{a}$ Catalyst loading in mol\%. ${ }^{b} \mathrm{dr}$ of crude product determined by ${ }^{1} \mathrm{H}$ NMR spectroscopic analysis. ${ }^{c}$ Isolated yields given as a mixture of diastereoisomers. Only the major diastereoisomer is shown. ${ }^{d}$ er of major diastereoisomer determined by chiral HPLC analysis. ${ }^{e}$ Oxidation reaction carried out for 24 h. ${ }^{f}$ After oxidation was complete the reaction mixture was cooled to $-10{ }^{\circ} \mathrm{C}$ and THF was added, such that the second step was carried out in a 3:1 mixture of THF:MeCN.

Reaction scope and generality. With an optimized sequential photoredox/Lewis base-catalyzed procedure in hand, the generality of this process was investigated, with the scope of the ester component examined first (Table 5). For the range of substituted arylacetic PNP esters studied, both the position and electronic nature of the substituent markedly influenced their 
reactivity and product enantioselectivity, while the product diastereoselectivity remained at approximately 75:25 dr. Substitution at the 3-position of the aromatic ring was successful, giving 3-methyl substituted 25 in $85 \%$ yield and er $_{\text {major }\left(2 R, 1^{\prime} S\right)}$ 90:10. Introduction of a methyl substituent at the 2-position however had a deleterious effect on reactivity: 2-methyl substituted 26 was obtained in a reduced 51\% yield and er $_{\text {major }}$ $\left(2 R, 1^{\prime} S\right) 78: 22$. Reaction of the phenylacetic acid derivative in this protocol worked well, giving 27 in $81 \%$ yield and $\mathrm{er}_{\text {major }}$ $\left(2 R, 1^{\prime} S\right) 92: 8$. Aromatic rings bearing an electron-donating groups were well tolerated, with 4-methoxy substitution giving $\mathbf{2 8}$ in $70 \%$ yield and er $_{\text {major }\left(2 R, 1^{\prime} S\right)} 94: 6$. A 3-methoxy substituted aromatic ring gave 29 in $56 \%$ yield and $\operatorname{er}_{\text {major }\left(2 R, 1^{\prime} S\right)} 91: 9$, however attempts to include an 2-methoxy substituent resulted in a significant reduction in yield, with the desired product difficult to isolate. ${ }^{38}$ Introduction of an electron-withdrawing $4-\mathrm{CF}_{3}$ substituted aromatic gave reduced reactivity, making it necessary to increase the $\mathbf{1} \cdot \mathrm{HCl}$ loading to $20 \mathrm{~mol} \%$, ${ }^{39}$ giving $\mathbf{3 0}$ in
$76 \%$ yield but with reduced er ( $\left.\mathrm{er}_{\text {major }\left(2 R, 1^{\prime} S\right)} 76: 24\right)$. 4-Bromo, 4-phenyl and 2-naphthyl substitutions were all well tolerated to give 31, 32 and $\mathbf{3 3}$ in approximately $80 \%$ yield and $\mathrm{er}_{\text {major }}$ $\left(2 R, 1^{\prime} S\right)$ 90:10, 84:16 and 91:9 respectively. In contrast, 1naphthyl substitution required $10 \mathrm{~mol} \% \mathbf{1} \cdot \mathrm{HCl}$ catalyst loading, giving 34 in $61 \%$ yield and $\mathrm{er}_{\text {major }\left(2 R, 1^{\prime} S\right)} 82: 18$. A 3thiophene substituent was tolerated, giving $\mathbf{3 5}$ in $85 \%$ yield and $\mathrm{er}_{\text {major }\left(2 R, 1^{\prime} S\right)} 92: 8$. Although alkyl substituted 4-nitrophenyl esters did not prove compatible with this methodology, ${ }^{26}$ alkenyl-substituted 4-nitrophenyl esters were compatible, but required $10 \mathrm{~mol} \% \mathbf{1} \cdot \mathrm{HCl}$ for optimal product yields, providing 36 and 37 in 64\% and 73\% yield and good enantioselectivity. Alternative nucleophilic amines to were also examined to prepare a range of isolable amide derivatives. Addition of pyrrolidine, $N$-Boc piperazine and morpholine resulted in the corresponding amides 38, 39 and 40 in excellent yield (79-86\%), and comparable stereoselectivity $\left(\sim 75: 25 \mathrm{dr}\right.$, and $\mathrm{er}_{\text {major }\left(2 R, 1^{\prime} S\right)}$ 95:5).

Table 5. Scope of the sequential photoredox/isothiourea-catalysis: variation of PNP ester and amine nucleophile
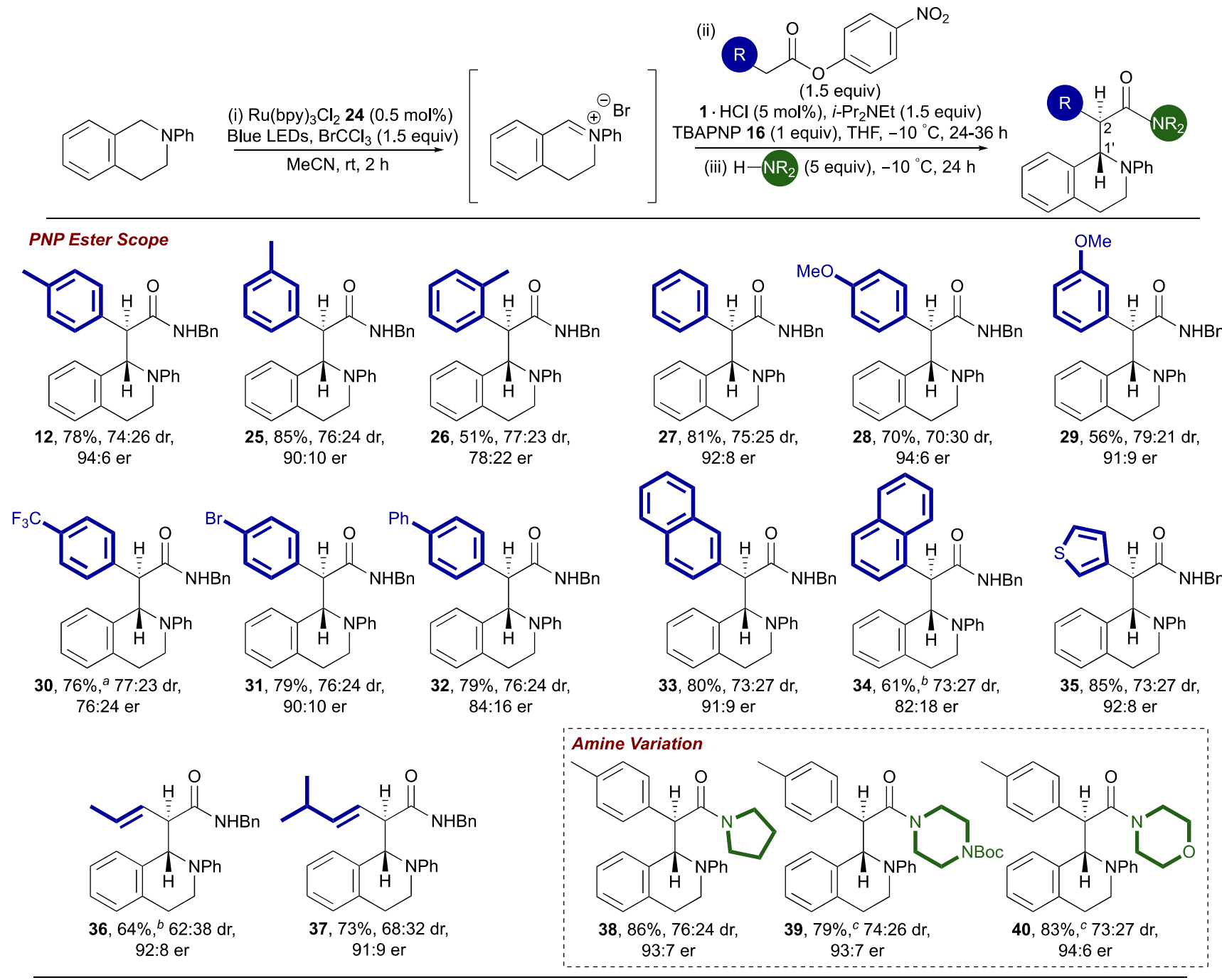

The er of the major diastereoisomer is stated. For the er of the minor diastereoisomer, see SI. ${ }^{a} 20 \mathrm{~mol} \% \mathbf{1} \cdot \mathrm{HCl}$ catalyst loading. ${ }^{b} 10 \mathrm{~mol} \% \mathbf{1} \cdot \mathrm{HCl}$ catalyst loading. ${ }^{c} 10$ equiv of amine used for quench. 
Further studies probed the scope of this process with respect to skeletal variation within the tetrahydroisoquinoline (Table 6). Substituent variation of the carbocylic skeleton showed that incorporation of 6,7-(MeO) $)_{2}$ substituents gave products 41 and 42 with excellent yields but reduced enantioselectivity with respect to 12. However, incorporation of either 5- or 7-Cl substituents proceeded with high enantioselectivity to give $\mathbf{4 3}$ and 44.

Table 6. Scope with variation in $\mathrm{N}$-aryl tetrahydroisoquinoline substrate
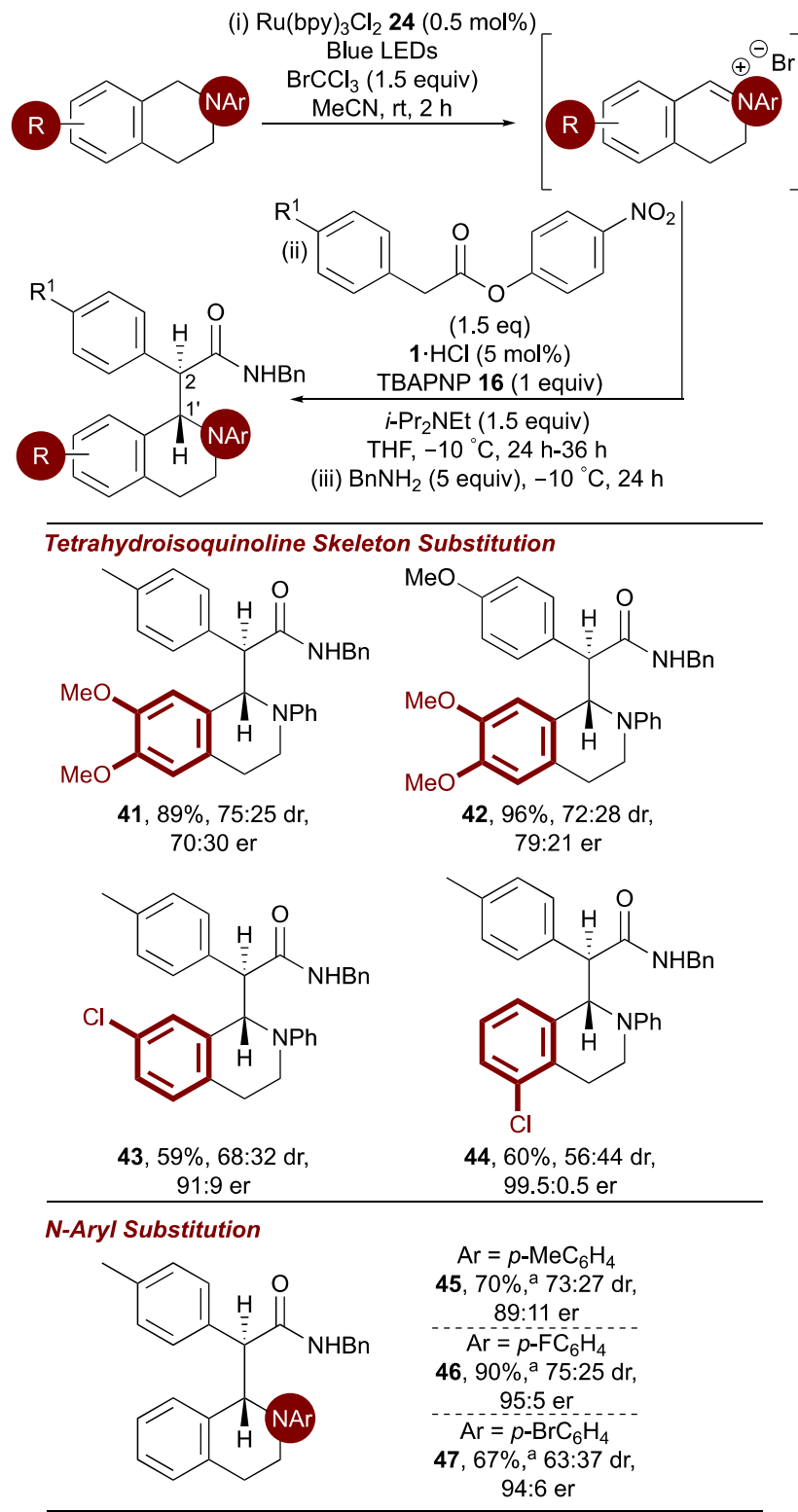

The er of the major diastereoisomer is stated. For the er of the minor diastereoisomer, see SI. ${ }^{a} 20 \mathrm{~mol} \% \mathbf{1} \cdot \mathrm{HCl}$ catalyst loading.

Variation of the $N$-substituent showed that while oxidation was successful with an $N$-methyl substituent, no conversion to the desired product was observed after the organocatalytic step. Incorporating a 4-methyl substituent gave $\mathbf{4 5}$ in $70 \%$ yield and $\mathrm{er}_{\text {major }(2 R, 1 ' \mathrm{~S})} 89: 11$. Introduction of a 4-fluoro substituent was well tolerated, giving 46 in $90 \%$ yield and excellent enatioselectivity ( $\left.\mathrm{er}_{\text {major }\left(2 R, 1^{\prime} S\right)} 95: 5\right)$, while 4-bromo substituent gave 47 in $67 \%$ yield and er $_{\text {major }\left(2 R, 1^{\prime} S\right)} 94: 6$. Unfortunately, substrates bearing an electron-withdrawing (4-CF 3 phenyl) and electron-donating (4-methoxyphenyl) aromatic $N$-substitution were unsuccessful, indicating limited electronic tolerance of the $N$-aryl substituent within this protocol.

\section{CONCLUSION}

In conclusion, the enantioselective isothiourea-catalyzed addition of 4-nitrophenyl esters to tetrahydroisoquinoline-derived iminium ions has been demonstrated using ammonium enolate catalysis. This methodology does not rely on an intramolecular nucleophile to achieve catalyst turnover, instead the 4nitrophenoxide expelled through $\mathrm{N}$-acylation of the 4nitrophenyl ester is able to re-enter the catalytic cycle to facilitate turnover of the catalyst. Control studies showed that reaction enantioselectivity was markedly dependent upon the nature of the iminium counterion. Extensive optimization lead to a sequential photoredox/isothiourea-catalyzed reaction being adopted, leading to the synthesis of substituted tetrahydroisoquinolines in high yield and excellent er. The substrate scope with respect to arylacetic and alkenylacetic 4-nitrophenyl esters, variation of the carbocyclic and $N$-aryl groups within the tetrahydroisoquinoline skeleton, as well as amine nucleophilic quench has been examined. Current work in our laboratory is focused on further applications of using in situ generated aryloxides to promote catalyst turnover in Lewis base catalysis. $^{40}$

\section{AUTHOR INFORMATION}

\section{Corresponding Author}

*E-mail: ads10@st-andrews.ac.uk

Notes

The authors declare no competing financial interest.

\section{ASSOCIATED CONTENT}

Supporting Information (SI). Experimental procedures, characterization data, copies of NMR spectra and HPLC chromatograms. This material is available free of charge via the Internet at http://pubs.acs.org.

\section{ACKNOWLEDGMENT}

We thank AstraZeneca and the EPSRC (grant codes EP/M506631/1; J.N.A. and EP/J018139/1; A.B.F.) for funding. The European Research Council under the European Union's Seventh Framework Programme (FP7/2007-2013) ERC Grant Agreement No. 279850 is also acknowledged. A.D.S. thanks the Royal Society for a Wolfson Research Merit Award. We also thank the EPSRC UK National Mass Spectrometry Facility at Swansea University.

\section{REFERENCES}

(1) (a) Gaunt, M. J.; Johansson, C. C. C. Chem. Rev. 2007, 107, 5596-5605. (b) Morrill, L. C.; Smith, A. D. Chem. Soc. Rev. 2014, 43, 6214-6226.

(2) (a) Fu, G. Acc. Chem. Res. 2000, 33, 412-420. (b) France, S.; Guerin, D. J.; Miller, S. J.; Lectka, T. Chem. Rev. 2003, 103, $2985-$ 3012. (c) Taylor, J. E.; Bull, S. D.; Williams, J. M. J. Chem. Soc. Rev. 2012, 41, 2109-2121. (d) Merad, J.; Pons, J.-M.; Chuzel, O.; Bressy, C. Eur. J. Org. Chem. 2016, 5589-5610.

(3) Denmark, S. E.; Beutner, G. L. Angew. Chem. Int. Ed. 2008, 47, 1560-1638.

(4) Paull, D. H.; Weatherwax, A.; Lectka, T. Tetrahedron 2009, 65, 6771-6803 and references therein. 
(5) (a) Cortez, G. S.; Tennyson, R. L.; Romo, D. J. Am. Chem. Soc. 2001, 123, 7945-7946. (b) Oh, S. H.; Cortez, G. S.; Romo, D. J. Org. Chem. 2005, 70, 2835-2838. (c) Henry-Riyad, H.; Lee, C.; Purohit, V. C.; Romo, D. Org. Lett. 2006, 8, 4363-4366. (d) Morrill, L. C.; Stark, D. G.; Taylor, J. E.; Smith, S. R.; Squires, J. A.; D'Hollander, A. C. A.; Simal, C.; Shapland, P.; O'Riordan, T. J. C.; Smith, A. D. Org. Biomol. Chem. 2014, 12, 9016-9027. (e) Yeh, P.-P.; Daniels, D. S. B.; Fallan, C.; Gould, E.; Simal, C.; Taylor, J. E.; Slawin, A. M. Z.; Smith, A. D. Org. Biomol. Chem. 2015, 13, 2177-2191. (f) Stark, D. G.; Young, C. M.; O'Riordan, T. J. C.; Slawin, A. M. Z.; Smith, A. D. Org. Biomol. Chem. 2016, 14, 8068-8073.

(6) (a) Morrill, L. C.; Ledingham, L. A.; Couturier, J.-P.; Bickel, J.; Harper, A. D.; Fallan, C.; Smith, A. D. Org. Biomol. Chem. 2014, 12, 624-636. (b) Stark, D. G.; Morrill, L. C.; Cordes, D. B.; Slawin, A. M. Z.; O'Riordan, T. J. C.; Smith, A. D. Chem. Asian J. 2016, 11, 395400

(7) Young, C. M.; Stark, D. G.; West, T. H.; Taylor, J. E.; Smith, A. D. Angew. Chem. Int. Ed. 2016, 55, 14394-14399.

(8) (a) Taggi, A. E.; Hafez, A. M.; Wack, H.; Young, B.; Drury, W. J.; Lectka, T. J. Am. Chem. Soc. 2000, 122, 7831-7832. (b) Wilson, J. E.; Fu, G. C. Angew. Chem. Int. Ed. 2004, 43, 6358-6360. (c) Purohit, V. C.; Malta, A. S.; Romo, D. J. Am. Chem. Soc. 2008, 130, 1047810479. (d) Leverett, C. A.; Purohit, V. C.; Romo, D. Angew. Chem. Int. Ed. 2010, 49, 9479-9483. (e) Smith, S. R.; Douglas, J.; Prevet, H.; Shapland, P.; Slawin, A. M. Z.; Smith, A. D. J. Org. Chem. 2014, 79, 1626-1639. (f) Morrill, L. C.; Smith, S. M.; Slawin, A. M. Z.; Smith, A. D. J. Org. Chem. 2014, 79, 1640-1655.

(9) (a) Hesping, L.; Biswas, A.; Daniliuc, C. G.; Mück-Lichtenfeld, C.; Studer, A. Chem. Sci. 2015, 6, 1252-1257. (b) Li, B.-S.; Wang, Y.; Jin, Z.; Chi, Y. R. Chem. Sci. 2015, 6, 6008-6012. (c) Smith, S. R.; Fallan, C.; Taylor, J. E.; McLennan, R.; Daniels, D. S. B.; Morrill, L. C.; Slawin, A. M. Z.; Smith, A. D. Chem. Eur. J. 2015, 21, 1053010536.

(10) (a) Bekele, T.; Shah, M. H.; Wolfer, J.; Abraham, C. J.; Weatherwax, A.; Lectka, T. J. Am. Chem. Soc. 2006, 128, 1810-1811. (b) Xu, X.; Wang, K.; Nelson, S. G. J. Am. Chem. Soc. 2007, 129, 11690-11691. (c) Belmessieri, D.; Morill, L. C.; Simal, C.; Slawin, A. M. Z.; Smith, A. D. J. Am. Chem. Soc. 2011, 133, 2714-2720. (d) Simal, C.; Lebl, T.; Slawin, A. M. Z.; Smith, A. D. Angew. Chem. Int. Ed. 2012, 51, 3653-3657. (e) Kasten, K.; Cordes, D. B.; Slawin, A. M. Z.; Smith, A. D. Eur. J. Org. Chem. 2016, 21, 3619-3624.

(11) Hafez, A. M.; Taggi, A. E.; Wack, H.; Esterbrook, J.; Lectka, T. Org. Lett. 2001, 3, 2049-2051.

(12) For a short review on aryloxide-promoted catalyst turnover in Lewis base organocatalysis, see: Hartley, W. C.; O'Riordan, T. J. C.; Smith, A. D. Synthesis 2017, 49, 3303-3310.

(13) (a) Wack, H.; Taggi, A. E.; Hafez, A. M.; Drury, W. J.; Lectka, T. J. Am. Chem. Soc. 2001, 123, 1531-1532. (b) Taggi, A. E.; Wack, H.; Hafez, A. M.; France, S.; Lectka, T. Org. Lett. 2002, 4, 627-629. (c) France, S.; Wack, H.; Taggi, A. E.; Hafez, A. M.; Wagerle, T. R.; Shah, M. H.; Dusich, C. L.; Lectka, T. J. Am. Chem. Soc. 2004, 126, 4245-4255. (d) Bernstein, D.; France, S.; Wolfer, J.; Lectka, T. Tetrahedron: Asymmetry 2005, 16, 3481-3483. For aryloxide generated in situ for N-heterocyclic carbene turnover, see: (e) Douglas, J.; Ling, K. B.; Concellón, C.; Churchill, G.; Slawin, A. M. Z.; Smith, A. D. Eur. J. Org. Chem. 2010, 5863-5869. (f) Concellón, C.; Duguet, N.; Smith, A. D. Adv. Synth. Catal. 2009, 351, 3001-3009.

(14) Kawanaka, Y.; Phillips, E. M.; Scheidt, K. A. J. Am. Chem. Soc. 2009, 131, 18028-18029.

(15) (a) Cheng, J.; Huang, Z.; Chi, Y. R. Angew. Chem. Int. Ed. 2013, 52, 8592-8596. (b) Hao, L.; Chen, S.; Xu, J.; Tiwari, B.; Fu, Z.; Li, T.; Lim; J.; Chi, Y. R. Org. Lett. 2013, 15, 4956-4959. (c) Fu, Z.; Xu, J.; Zhu, T.; Leong, W. W. Y.; Chi, Y. R. Nat. Chem. 2013, 5, 835-839.

(16) (a) Hao, L.; Du, Y.; Lv, H.; Chen, X.; Jiang, H.; Shao, Y.; Chi, Y. R. Org. Lett. 2012, 14, 2154-2157. (b) Hao, L.; Chan, W. C.; Ganguly, R.; Chi, Y. R. Synlett 2013, 24, 1197-1200; (c) Hao, L.; Chen, X.; Chen, S.; Jiang, K.; Torres, J.; Chi, Y. R. Org. Chem. Front. 2014, $1,148-150$.

(17) West, T. H.; Daniels, D. S. B.; Slawin, A. M. Z.; Smith, A. D. J. Am. Chem. Soc. 2014, 136, 4476-4479.
(18) (a) West, T. H.; Walden, D. M.; Taylor, J. E.; Brueckner, A. C.; Johnston, R. C.; Cheong, P. H.-Y.; Lloyd-Jones, G. C.; Smith, A. D. J. Am. Chem. Soc. 2017, 139, 4366-4375. (b) Vora, H. U.; Rovis, T. J. Am. Chem. Soc. 2007, 129, 13796-13797. (c) Wheeler, P.; Vora, H. U.; Rovis, T. Chem. Sci. 2013, 4, 1674-1679.

(19) Lee, S. Y.; Neufeind, S.; Fu, G. C. J. Am. Chem. Soc. 2014 136, 8899-8902.

(20) Schwarz, K. J.; Amos, J. L.; Klein, J. C.; Do, D. T.; Snaddon, T. N. J. Am. Chem. Soc. 2016, 138, 5214-5217.

(21) Jiang, X.; Beiger, J. J.; Hartwig, J. F. J. Am. Chem. Soc. 2017, 139, 87-90.

(22) For $\mathrm{S} \cdots \mathrm{O}$ interactions as control elements in isothiourea catalysis, see: (a) Robinson, E. R. T.; Walden, D. M.; Fallan, C.; Greenhalgh, M. D.; Cheong, P. H.-Y.; Smith, A. D. Chem. Sci. 2016, 7, 6919-6927. (b) Abbasov, M. E.; Hudson, B. M.; Tantillo, D. J.; Romo, D. J. Am. Chem. Soc. 2014, 136, 4492-4495. (c) Liu, P.; Yang, X.; Birman, V. B.; Houk, K. N. Org. Lett. 2012, 14, 3288-3291. (d) Birman, V. B.; Li, X.; Han, Z. Org. Lett. 2007, 9, 37-40. For an alternative use of $\mathrm{S} \cdots \mathrm{O}$ interactions in asymmetric synthesis, see: (e) Nagao, Y.; Miyamoto, S.; Miyamoto, M.; Takeshige, H.; Hayashi, K.; Sano, S.; Shiro, M.; Yamaguchi, K.; Sei, Y. J. Am. Chem. Soc. 2006, 128, 9722-9729. For a recent computational manuscript on the origin of S $\bullet$ O interactions see Pascoe, D. J., Ling, K. B., Cockcroft, S. L. J. Am. Chem. Soc. 2017, 139, 15160-15167.

(23) (a) Tsang, A. S.-K.; Todd, M. H. Tetrahedron Lett. 2009, 50, 1199-1202. (b) Tsang, A. S.-K.; Jensen, P.; Hook, J. M.; Hashmi, A. S. K.; Todd, M. H. Pure App. Chem. 2011, 83, 655-665.

(24) The PNP ester product is susceptible to hydrolysis upon workup. Adding $\mathrm{BnNH}_{2}$ after the organocatalysis step ensures full conversion to the more stable amide 12. The isolated yields were comparable to that analyzed by ${ }^{1} \mathrm{H}$ NMR spectroscopy of the crude mixture using 1,4-dinitrobenzene as an internal standard.

(25) The relative configurations of both 4-bromo-31 (major) and 4bromo-31 (minor) diastereoisomers were confirmed by single crystal $\mathrm{X}$-ray diffraction analysis. CCDC 1554610 contains the supplementary crystallographic data for $\mathbf{3 1}$ (major) and CCDC 1554609 for $\mathbf{3 1}$ (minor), with all other substrates assigned by analogy. See SI for further details. The absolute configuration was assigned by analogy to the facial selectivity of all other isothiourea-derived ammonium enolates, see references: 5 (d)-(f), 6, 7, 8 (e)-(f), 9 (c), 10 (c)-(d), 17, 18 (a), 20 and 21.

(26) See SI for full experimental details.

(27) Additional control reactions were performed to track the origin of the minor diastereoisomer. A small amount of the PNP ester product was obtained, and its dr determined. This product was then subjected to a nucleophilic quench with $\mathrm{BnNH}_{2}$; the dr remained unaltered and was consistent with that of amide product $\mathbf{1 2}$ isolated from a standard reaction. The $\mathbf{1} \cdot \mathrm{HCl}$-catalyzed reaction prior to the $\mathrm{BnNH}_{2}$ quench was monitored by ${ }^{1} \mathrm{H}$ NMR spectroscopy, and it was found that the $\mathrm{dr}$ of the corresponding PNP ester product as it was forming was the same as that of the isolated amide product $(73: 27 \mathrm{dr})$.

(28) (a) Zeitler, K. Angew. Chem. Int. Ed. 2009, 48, 9785-9789. (b) Yoon, T. P.; Ischay, M. A.; Du, J. Nat. Chem. 2010, 2, 527-532. (c) Xuan, J.; Xiao, W.-J. Angew. Chem. Int. Ed. 2012, 51, 6828-6838. (d) Narayanam, J. M. R.; Stephenson, C. R. J. Chem. Soc. Rev. 2011, 40, 102-113. (e) Tucker, J. W.; Stephenson, C. R. J. J. Org. Chem. 2012, 77, 1617-1622. (f) Prier, C. K.; Rankic, D. A.; MacMillan, D. W. C. Chem. Rev. 2013, 113, 5322-5363. (g) Shaw, M. H.; Twilton, J.; MacMillan, D. W. C. J. Org. Chem. 2016, 81, 6898-6926.

(29) Hopkinson, M. N.; Sahoo, B.; Li, J.-L.; Glorius, F. Chem. Eur J. 2014, 20, 3874-3886.

(30) Nicewicz, D. A.; MacMillan, D. W. C. Science 2008, 322, $77-$ 80 .

(31) DiRocco, D. A.; Rovis, T. J. Am. Chem. Soc. 2012, 134, 80948097.

(32) (a) Rueping, M.; Vila, C.; Koenigs, R. M.; Poscharny, K.; Fabry, D. C. Chem. Commun. 2011, 47, 2360-2362. (b) Silvi, M.; Arceo, E.; Jurberg, I. D.; Cassani, C.; Melchiorre, P. J. Am. Chem. Soc. 2015, 137, 6120-6123.

(33) Bergonzini, G.; Schindler, C. S.; Wallentin, C.-J.; Jacobsen, E. N.; Stephenson, C. R. J. Chem. Sci. 2014, 5, 112-116. 
(34) Feng, Z.-J.; Xuan, J.; Xia, X.-D.; Ding, W.; Guo, W.; Chen, J.-R.; Zou, Y.-Q.; Lu, L.-Q.; Xiao, W.-J. Org. Biomol. Chem. 2014, $12,2037-2040$

(35) Franz, J. F.; Kraus, W. B.; Zeitler, K. Chem. Commun. 2015, $51,8280-8283$.

(36) The generality of protocol for the oxidation using $\mathrm{BrCCl}_{3}$ and blue LEDs in the absence of a photocatalyst was explored with some substrates, but yields were lower than using the photoredox procedure. See SI for further details.

(37) For an example of nucleophilic trapping of iminium intermediates derived from the oxidation of tetrahydroisoquinolines, see: Freeman, D. B.; Furst, L.; Condie, A. G.; Stephenson, C. R. J. Org. Lett. 2012, 14, 94-97.
(38) The amide product bearing an 2-methoxy substitution on the

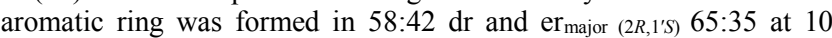
$\mathrm{mol} \% \mathbf{1} \cdot \mathrm{HCl}$ catalyst loading. Multiple attempts at purification by column chromatography failed to separate the desired product from unidentified side products, with an approximate isolated yield of $32 \%$. See SI for further details.

(39) A reaction involving 4- $\mathrm{CF}_{3}$ PNP ester with iminium bromide 18 in the absence of organocatalyst $\mathbf{1} \cdot \mathrm{HCl}$ gave the corresponding amide product 30 in $68 \%$ isolated yield and $58: 42 \mathrm{dr}$. This is consistent with a competitive base-mediated background reaction being operative under these reaction conditions.

(40) The research data underpinning this publication can be accessed at: http://dx.doi.org/10.17630/12bb1529-4947-4d75-b607$\underline{583606 \mathrm{a} 66652}$.

\section{Table of Contents (TOC) Graphic}

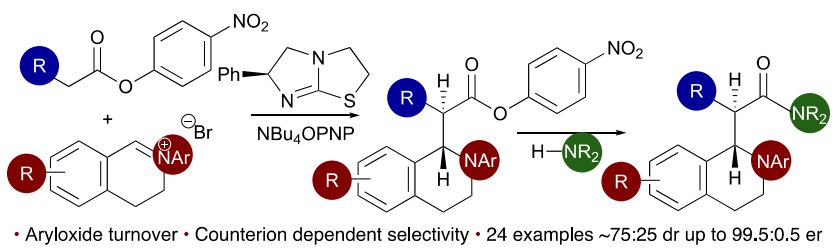

